Ann. rheum. Dis. (1966), 25, 623

SESSION II

\title{
PRIMARY HYPERURICAEMIA AND GOUT
}

\author{
(Chairman: DR. J. J. R. DUTHIE)
}

\section{COMPARISON OF ALLOPURINOL AND PROBENECID}

\author{
BY \\ J. T. SCOTT* \\ London
}

After the introduction of allopurinol by the previous speakers, other clinical trials were carried out, and our own preliminary experience at the Postgraduate Medical School was presented to this Society 2 years ago (Hall, Holloway, and Scott, 1964). These studies confirmed the ability of allopurinol to lower the levels of serum uric acid (SUA) and urinary uric acid (UUA) rapidly with an increase in urinary oxypurine excretion. This increase, however, was not as large as the fall in UUA, so that there was a fall in overall purine excretion. In one or two patients severe gouty arthritis followed the commencement of therapy.

Our further clinical investigations have followed two directions:

(a) A therapeutic trial comparing the long-term effects of allopurinol with those of conventional uricosuric treatment in patients with uncomplicated gout;

(b) The effect of allopurinol given to patients in whom for one reason or another the drug was considered to be specially indicated.

It is the first of these which I will now briefly present: a detailed account of all our results is being published elsewhere (Scott, Hall, and Grahame, 1966).

\section{Material}

For the comparative trial of allopurinol against uricosuric treatment, out-patients were selected in whom gout was, as far as could be determined, primary and uncomplicated except in some cases with minor degrees of renal functional impairment. All were men. Most of them were new clinic referrals and had not been given any consistent form of uricosuric therapy; none had received such treatment during the 6 months preceding the trial. Patients were allocated to treatment with either allopurinol or uricosuric drugs by reference to the last digit

*Charing Cross and West London Hospitals, London. of their hospital number; those with an even digit received allopurinol and those with an odd digit uricosuric therapy. By this method of allocation 21 patients started allopurinol treatment and 19 uricosuric treatment. One patient taking allopurinol defaulted from follow-up. One patient taking uricosuric therapy defaulted from follow-up and one left the district so that adequate follow-up was impossible. The results therefore apply to twenty patients taking allopurinol (Group I) and seventeen taking uricosuric therapy (Group II). Characteristics of the patients studied are shown in Tableg I, which shows that the subjects in the two treatment groups were reasonably comparable in all respects.

\section{Drugs and Dosage}

Allopurinol was given in an initial dose of $300 \mathrm{mg}$. daily, but this was increased where necessary. At present twelve of the patients are still taking $\mathbf{3 0 0} \mathrm{mg}$. daily, in six the dose has been increased to $400 \mathrm{mg}$. daily, and in two to $600 \mathrm{mg}$. daily.

The drug selected for uricosuric treatment was probenecid (Benemid) which was started in a dose of $1 \mathrm{~g}$. daily rising to $2 \mathrm{~g}$. daily after 2 weeks of treatment. (This order of dose is usually necessary to achieve an adequate uricosuric response). Of the seventeen patients in this group, one has continued to take $1 \mathrm{~g}$. daily and eleven have continued to take $2 \mathrm{~g}$. daily. In five patients the uricosuric treatment has been changed to sulphinpyrazone (Anturan) $400 \mathrm{mg}$. daily, because probenecid tablets were found to cause flatulence, or pruritus, or to be difficult to swallow or distasteful.

In regulating the dose of these drugs it was aimed to produce a satisfactory fall in levels of SUA and UUA, but no attempt was made to advance the dosage beyond this. By the method of uric acid estimation used (Technicon Auto Analyser), the upper limit of normal for men and post-menopausal women is $6 \mathrm{mg}$. $/ 100 \mathrm{ml}$. and that for premenopausal women $5 \mathrm{mg}$. $/ 100 \mathrm{ml}$. A fall which brings the uric acid level into this range is considered satisfactory.

Because severe acute attacks of gout tend to occur for a time after the serum uric acid level has been lowered, patients were instructed to take colchicine $0.5 \mathrm{mg}$. two or three times daily while treatment with either drug was 
commenced. In those who became free of symptoms, colchicine was withdrawn several months after the last attack of gout, but it is anticipated that treatment with either allopurinol or uricosuric drugs will be continued indefinitely in the absence of any toxic effects. No special diet was prescribed for these patients. In accordance with our usual practice they were told which foods contain a high purine content, and they were advised to avoid an excessive intake of these foods and of alcohol.

\section{Duration of Follow-up}

The mean duration of follow-up for patients taking allopurinol has been 18.6 months (range 10 to 23), and for those taking probenecid $19 \cdot 6$ months (range 11 to 24 ). After initial assessment, patients have been seen at intervals of 2 weeks, 1 months, 2 months, and 3 months; and at 3-monthly intervals thereafter.

\section{Results}

(1) Frequency of Acute Gout.-It is difficult to be precise about the frequency or severity of attacks of gout. All patients were having recurrent attacks before treatment was started (Table I) and the overall effect has been to reduce the number of attacks in both treatment groups. As mentioned above, all patients were given colchicine. Of the twenty patients receiving allopurinol, nine have had no further gout since starting treatment, six have had one further attack between 1 and 9 months after starting treatment, four had two further attacks 2 and 15 months after starting treatment (one mostly in the early months), and one patient continued to have severe attacks for 6 months after starting treatmen but has been free of gout since. Of the seventeen? patients taking uricosuric treatment, eight have had? no further gout after starting treatment, six had one further attack occurring between 2 weeks and 150 months after starting treatment (one of these has temporarily stopped his tablets because of pain from his duodenal ulcer), two had two attacks at between 2 weeks and 17 months after starting treatment, and one had three further attacks occurring between $\mathfrak{F}^{p}$ and 5 months after starting treatment.

In both treatment groups, therefore, about half the patients had no further gout after starting treatmenfw and in the others attacks have become much les\$ frequent. Such attacks as did occur in these earlo months, however, appeared to be of considerabler severity.

(2) Tophi.-As will be evident from the descrip음 tion of the patients, most of the subjects in this comparative trial did not have advanced tophaceous gout. In two of the three patients with very smald tophi taking allopurinol these have disappeared, an the same has occurred in one of the two patients with tophi taking probenecid.

(3) Serum Uric Acid.-Drug dosage was regtidaz ted to some extent to produce a satisfactory falbi the SUA level without trying to go beyond Table II shows the mean SUA level in each treatmeng group (a) before treatment was started, (b) 2 weeks

TABLE I

CLINICAL PARTICULARS OF PATIENTS STUDIED

\begin{tabular}{|c|c|c|c|c|c|c|}
\hline Group & & & & & $\stackrel{\text { I }}{\text { Allopurinol }}$ & Uricosuric Treatment \\
\hline 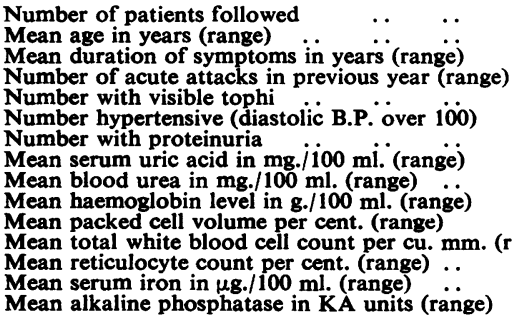 & $\begin{array}{l}\cdots \\
\cdots \\
\cdots \\
\cdots \\
\cdots \\
\cdots \\
\therefore \\
\text { range) } \\
\cdots \\
\cdots\end{array}$ & $\begin{array}{l}\cdots \\
\cdots \\
\cdots \\
\cdots \\
\cdots \\
\cdots \\
\cdots \\
\cdots \\
\cdots \\
\cdots \\
\cdots\end{array}$ & $\begin{array}{l}\cdots \\
\cdots \\
\cdots \\
\cdots \\
\cdots \\
\cdots \\
\cdots \\
\cdots \\
\cdots \\
\cdots\end{array}$ & $\begin{array}{l}\cdots \\
\cdots \\
\cdots \\
\cdots \\
\cdots \\
\cdots \\
\cdots \\
\cdots \\
\cdots \\
\cdots\end{array}$ & $\begin{array}{c}20 \\
54(27-78) \\
7 \cdot 3(0 \cdot 2-31) \\
1-12 \\
3 \\
2 \\
4 \\
9 \cdot 3(7 \cdot 5-10 \cdot 6) \\
35(15-56) \\
14 \cdot 7(12 \cdot 8-16 \cdot 9) \\
43 \cdot 9(37-49) \\
5,600(5,000-8,000) \\
2 \cdot 0(1 \cdot 0-5 \cdot 2) \\
119(74-226) \\
8 \cdot 8(5-19)\end{array}$ & $\begin{array}{c}17 \\
54(38-76) \\
8 \cdot 9(1-29) \\
1-10 \\
2 \\
2 \\
2 \\
8 \cdot 5(7 \cdot 5-11 \cdot 7) \\
41 \quad(25-61) \\
15 \cdot 0(12 \cdot 8-17 \cdot 0) \\
44 \cdot 7(38-54) \\
6,800(5,000-10,000) \\
1 \cdot 9(0 \cdot 8-4 \cdot 2) \\
109(32-158) \\
7 \cdot 9(4-13)\end{array}$ \\
\hline
\end{tabular}

TABLE II

EFFECT OF TREATMENT ON SERUM URIC ACID LEVEL (mg. $/ 100 \mathrm{ml}$.)

\begin{tabular}{|c|c|c|c|c|c|c|}
\hline \multirow{2}{*}{ Group } & \multicolumn{3}{|c|}{$\stackrel{\text { I }}{\text { Allopurinol }}$} & \multicolumn{3}{|c|}{ Uricosuric Treatment } \\
\hline & $\begin{array}{c}\text { Before } \\
\text { Treatment }\end{array}$ & $\begin{array}{l}\text { After } 2 \\
\text { Weeks }\end{array}$ & $\begin{array}{c}\text { At Last } \\
\text { Estimation }\end{array}$ & $\begin{array}{c}\text { Before } \\
\text { Treatment }\end{array}$ & $\begin{array}{l}\text { After } 2 \\
\text { Weeks }\end{array}$ & $\begin{array}{c}\text { At Last } \\
\text { Estimation }\end{array}$ \\
\hline $\begin{array}{l}\text { Mean } \\
\text { Range }\end{array}$ & $\begin{array}{c}9 \cdot 3 \\
7 \cdot 5-10 \cdot 6\end{array}$ & $\begin{array}{l}5 \cdot 8 \\
4 \cdot 5-6 \cdot 9\end{array}$ & $\begin{array}{c}4 \cdot 7 \\
2 \cdot 6-5 \cdot 5\end{array}$ & $\begin{array}{c}8 \cdot 5 \\
7 \cdot 5-11 \cdot 7\end{array}$ & $\begin{array}{c}6 \cdot 3 \\
3 \cdot 9 \cdot 10 \cdot 8\end{array}$ & $\begin{array}{c}5 \cdot 2 \\
3 \cdot 8-7 \cdot 3\end{array}$ \\
\hline
\end{tabular}


after treatment was started, and (c) at the last examination of each patient. A satisfactory fall in SUA was achieved in most patients in both groups. None failed to show a fall in the SUA level. The falls produced with allopurinol have been rather greater than those produced with probenecid, and we have the distinct impression that allopurinol can produce a more rapid and greater fall in SUA than uricosuric drugs. From the therapeutic point of view, however, the clinical and biochemical response in both treatment groups has been satisfactory.

(4) Other Methods of Assessment.-Table III shows that no significant change took place in either treatment group with regard to blood urea, haemoglobin, packed cell volume, white cell count (the initial count was always normal), reticulocyte count, or serum iron. This last finding is of interest in relation to the report by Powell and Emmerson (1966) of an increase in hepatic storage iron in allopurinoltreated rats, of which we shall be hearing more later.

(5) Tests of Liver Function.--Serum alkaline phosphatase was measured at most times of assessment in King-Armstrong units (normal less than 14 units). In Group II (taking probenecid) the mean level before treatment was 7.9 units (range 4 to 13 ) and there was almost no change during therapy, the mean at the last assessment being 8.4 units (range 5 to 12). Five patients in this group showed a slight increase and five a slight decrease, and in seven the figure was unchanged. In Group I (taking allopurinol) the mean initial level was $8 \cdot 8$ units (range 5 to 19) and there was a mean increase of $2 \cdot 1$ units during the treatment period, the mean at the last assessment being 10.9 units (range 6 to 27). Of the twenty patients in this group, fifteen showed a slight rise in alkaline phosphatase levels, four were unchanged, and only one showed a decrease. Only one patient with a normal initial alkaline phosphatase showed an abnormal figure (16 units) at the last assessment and the small mean rise appeared to be of little signifi- cance; but it was thought desirable to carry out further tests of hepatic function. These additional tests had not been performed before treatment was begun, but the probenecid-treated Group II was available for comparison with patients who had been given allopurinol. Patients were recalled for the additional investigations after the latest assessment: sera were examined from all of the twenty patients in Group I and fourteen of the seventeen in Group II.

Serum albumin and globulin were normal in all patients. The colloidal gold test was normal in all patients. Thymol turbidity was normal (less than 4 units) in all patients (except one in Group II in whom it was 6 units). Serum bilirubin was normal (less than $1 \mathrm{mg} . / 100 \mathrm{ml}$.) in most patients, but lay between 1 and $2 \mathrm{mg}$. $/ 100 \mathrm{ml}$. in three patients from Group I and one from Group II.

Serum glutamic oxaloacetic transaminase was normal (less than 40 units) in all patients except one from each group, in both of whom it was 43 units. Serum glutamic pyruvic transaminase was normal (less than 30 units) in most patients, but was raised in four from Group I $(33,47,54$, and 68 units) and in one from Group II (41 units).

Bromsulphthalein retention (normal less than 5 per cent. at the end of 45 minutes) lay above 5 pero cent. in thirteen of the twenty patients in Group (mean 7.5 per cent.; range 2 to 15 ) and in twelve ofo fourteen patients in Group II (mean 9.7 per cent.; range 4 to 20). No reason for this high incidence of abnormal bromsulphthalein (BSP) retention in both treatment groups was discovered. None of the patients showed any clinical evidence of liver disease. Most of them gave a history of considerable alcohol consumption although none could be regarded as chronic alcoholics in the usual sense of the term. In view of this unexpected finding, we have gone on to examine BSP retention in a number of other patients with untreated gout and hyperuricaemia. Dr. Grahame will talk about this in the discussion.

TABLE III

RESULTS OF OTHER INVESTIGATIONS

\begin{tabular}{|c|c|c|c|c|}
\hline \multirow[t]{2}{*}{ Group } & \multicolumn{2}{|c|}{$\stackrel{\text { I }}{\text { Allopurinol }}$} & \multicolumn{2}{|c|}{ Uricosuric Treatment } \\
\hline & $\begin{array}{l}\text { Before } \\
\text { Therapy }\end{array}$ & $\begin{array}{c}\text { At Latest } \\
\text { Estimation }\end{array}$ & $\begin{array}{l}\text { Before } \\
\text { Therapy }\end{array}$ & $\begin{array}{l}\text { At Latest } \\
\text { Estimation }\end{array}$ \\
\hline 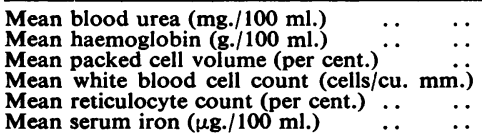 & $\begin{array}{c}35 \\
14 \cdot 7 \\
43 \cdot 9 \\
5,600 \\
2 \cdot 0 \\
119\end{array}$ & $\begin{array}{c}34 \\
13 \cdot 8 \\
46 \cdot 6 \\
5,800 \\
1 \cdot 8 \\
117\end{array}$ & $\begin{array}{c}41 \\
15 \cdot 0 \\
44 \cdot 7 \\
6,800 \\
1 \cdot 9 \\
109\end{array}$ & $\begin{array}{c}41 \\
14 \cdot 1 \\
45 \cdot 6 \\
6,300 \\
1 \cdot 9 \\
110\end{array}$ \\
\hline
\end{tabular}


(6) Radiology.-Patients had joint radiographs carried out before and during treatment, but during the comparatively short period in which they have so far been followed the only radiological change has occurred in two men taking allopurinol in whom the radiographs showed healing of bony lesions.

(7) Other Effects.-The questions of acute gout and liver function have already been considered. No serious side-effects have been encountered in either treatment group. In Group I two patients developed skin rashes which were slight and transient, disappearing while treatment was continued. One noticed mild spontaneous bruising (though no haematological abnormality was found). One complained of persistent dyspepsia. One had a mild leucoplakia-like lesion of the gums which also cleared while treatment was continued. The direct relation of all these minor symptoms to allopurinol itself is questionable, and in general tablets of allopurinol seemed readily acceptable.

In Group II one patient complained of difficulty in swallowing probenecid tablets, two of flatulence, one of finding the tablets distasteful, and one of pruritus. Treatment in these five patients was changed to sulphinpyrazone (Anturan) which they took without difficulty.

\section{Summary}

The results in this comparative trial so far show no clear advantage in either treatment group. It is possible that as time passes allopurinol may be found to possess long-term benefits, such as prevention of renal damage, or delayed toxic effects, but $\frac{\bar{\omega}}{\omega}$. of this we have as yet no indication.

In addition to the patients described, a further $\overrightarrow{\bar{F}}$ group has been given allopurinol because there wereo special features which precluded their entry into the음 comparative trial. These indications included vari- $-\bar{s}$ ous adverse reactions to uricosuric agents, inadequate ${ }_{\infty}^{\infty}$ control of gout by uricosuric treatment, severeon chronic gouty arthritis, renal failure, and uric acid stone formation. In general the biochemical and. clinical response to allopurinol in these patients has $\vec{\omega}$ been very satisfactory.

The present position is, therefore, that in early or uncomplicated gout there is little to choose between allopurinol and conventional uricosuric therapy.or There are several situations in which allopurinol does seem to be indicated, either alone or in combination? with uricosuric drugs:

(1) Severe tophaceous gout.

(2) Gout which is not controlled by uricosuric은 treatment.

(3) Intolerance to uricosuric drugs.

(4) Gout with known gross over-production of uric acid.

(5) Uric acid stone formation.

(6) Gout with advanced renal failure.

(7) Acute uric acid nephropathy.

Several of these situations will be discussed in detail by other speakers. 